\title{
Joel Best, Uso y abuso de las estadísticas. La distorsión en la percepción pública de los problemas sociales y políticos (Editorial Cuatro Vientos, Santiago, 2009, 194 pp.)
}

Josefina Correa Téllez*

En la actualidad las estadísticas constituyen un elemento central al momento de comprender y explicar los problemas sociales, así como también un recurso para presentarlos de manera simple a la opinión pública. La información estadística nos provee de modelos para abordar las complejidades del mundo, sin embargo, el discurso común tendería a pensar las estadísticas como datos objetivos de la realidad, facticidades indiscutibles. Ante esta situación, Joel Best plantea una advertencia. Más que datos objetivos del mundo, las estadísticas son productos de la actividad humana y en ese sentido son moldeables. No son simplemente números, sino construcciones sociales capaces de configurar visiones de mundo, darnos determinada idea de los hechos y las problemáticas sociales pudiendo convertirse, en algunos casos, en instrumentos eficaces de manipulación. En consecuencia, el primer objetivo de Best es desmitificar el papel y los malos usos de la estadística en la opinión pública a modo de advertencia para quienes se enfrentan a la lectura cotidiana de cifras en los medios.

Un segundo objetivo, ligado al primero, es promover la alfabetización estadística. Frente a su enseñanza matemática y técnica centrada en el cálculo y la lógica, en su procesamiento computacional y en sus aspectos interpretativos, el autor aboga por una perspectiva sociológica de la estadística que asume las cifras como productos humanos necesarios de contextualizar socialmente. Está preocupado por el proceso social que hay detrás de la construcción del dato, el que implica aspectos ideológicos, decisiones metodológicas, limitaciones presupuestarias, entre otros, los que afectan los resultados. Tal como plantea el autor: "nuestro foco está centrado en quién, cómo y por qué contabiliza y genera las cifras. También nos interesa saber cuáles audiencias consumen y utilizan esos datos. Más que los cálculos para llegar a las cifras, hemos intentado comprender su construcción social" (p. 181). La alfabetización estadística se propone, entonces, entregar herramientas que permitan un análisis crítico de las cifras a cualquier individuo.

Con el fin de mostrar los usos y abusos de las estadísticas, los errores comunes y los usos tendenciosos que en muchas ocasiones pasan desapercibidos para la opinión pública, el autor analizó una serie de datos producidos por distintos sectores sociales y publicados en diversos medios estadounidenses. De este análisis extrajo una clasificación de seis tipos de malas estadísticas, dedicando cada uno de los capítulos del libro a describirlas y

* Licenciada en Sociología, Universidad de Chile. 
ejemplificarlas con casos concretos. El primer capítulo está dedicado a las cifras que brillan por su ausencia, aquellos números que son relevantes para la comprensión de un fenómeno pero que no se consideraron al momento de decidir qué contabilizar. El capítulo dos se centra en las cifras engañosas más simples y comunes, que en lugar de informar producen confusión, como es el caso de promedios, porcentajes, correlaciones, y las representaciones gráficas de éstos. El capítulo tres aborda las cifras que asustan, las que en pos de llamar la atención magnifican temores y riesgos. El capítulo cuatro trabaja sobre las cifras acreditadas, estadísticas generadas por quienes son considerados socialmente una autoridad en la materia, que velan por la exactitud de los números y que se difunden por canales institucionales, pero que no deben confundirse con datos objetivos y definitivos, pues también obedecen a un proceso social de toma de decisiones sobre qué, cómo y por qué contabilizar. El capitulo cinco aborda las cifras mágicas, aquellos datos a los que se les otorga gran importancia tal como si tuvieran "el poder mágico de resumir y aclarar la realidad y darnos una base sólida para tomar decisiones" (p. 149). Finalmente están las cifras controversiales, aquellas que se transforman en el centro de discusiones entre posiciones contradictorias.

Ahora bien, más allá de presentar una clasificación de malas estadísticas el autor plantea, aunque no de manera sistemática y acabada, algunos temas de gran interés teórico para la discusión sobre la construcción social del dato y su presencia en la opinión pública, lo que parece relevante considerar.

El primero de ellos corresponde a la crítica que Best hace de la relación entre estadísticas y medios de comunicación, específicamente en lo que se refiere al mal uso que da la prensa a las estadísticas en cuanto a selección de información y énfasis de algunos datos en pos del impacto que estos puedan causar. No hay duda de la importancia que ha adquirido en las últimas décadas la opinión pública y, en ese contexto, cierta esencia competitiva del mercado de la opinión que lleva a que los temas -y los datos numéricos que los sustentan- compitan por un espacio de relevancia en base a lo atemorizantes, inquietantes y riesgosos que resulten para el público. La contracara de esta situación sería, para Best, una cultura individualista que requiere de la "democratización del riesgo" para interesarse por algunas temáticas.

El segundo tema que esboza el autor tiene que ver con la relación entre autoridad y estadísticas, centrándose en la credibilidad, validez y objetividad de la que gozarían los datos producidos y difundidos por ciertas instituciones dotadas de legitimidad ante la opinión pública. Si bien estas estadísticas merecen tal posición dada su exactitud y la confianza que existe en el modo en que se producen, se corre el riesgo de confundir estos números con datos objetivos y reales, sin mediar la pregunta por el proceso social que está detrás. Tanto en las producciones científicas como en aquellas estadísticas oficiales generadas por el poder político median decisiones en torno al proceso de contabilización, las que pueden estar permeadas no sólo por opciones metodológicas o teóricas, sino también por decisiones políticas. Tal como Best plantea, más que preguntarnos si las cifras son verdaderas, debemos cuestionar el cómo se llegó a determinado resultado.

Un tercer tema que plantea es la relación entre ciencia y estadísticas, introduciéndose en el proceso de decisiones de los científicos al momento de producir datos y los aspectos 
extracientíficos que entran en juego. Da cuenta de cómo las decisiones metodológicas y teóricas pueden estar mediadas por limitaciones presupuestarias o temáticas, derivadas tanto de la comunidad científica como de los temas que en un momento son de interés de políticas públicas. Menciona brevemente, además, el proceso de validación de datos para el conocimiento científico destacando la contraposición entre un desarrollo lento y juicioso del conocimiento científico producto del proceso de validación, frente a la difusión irreflexiva de resultados de investigaciones científicas en la prensa, la que se centra en descubrimientos impactantes y particulares, más que en el proceso dentro de la comunidad científica orientado hacia la validación de conocimientos generados anteriormente.

Es así como Best transita por una serie de temáticas y aborda un amplio abanico de producciones estadísticas, intentando mostrar que cualquiera puede incurrir en su mala utilización. Izquierdas y derechas, científicos, activistas políticos, medios de comunicación, y otros, pueden caer en malas prácticas ante lo cual hay que analizar sus cifras con ojo crítico. Así, la alfabetización estadística se vuelve necesaria. La finalidad, aumentar la crítica y la exigencia sobre el buen uso de las cifras para los distintos medios y sectores. ¿Y quién debería encargarse de esta educación?, la respuesta está en las ciencias sociales.

El trabajo de Best cumple el objetivo que se propone de advertir sobre la mala utilización de las estadísticas en la opinión pública. Se plantea como una guía para un público amplio proponiendo herramientas concretas para la crítica estadística, las que son insertadas en una discusión general sobre la construcción social del dato que incluye conceptos de ciencia, cultura, medios de comunicación y autoridad. De estos temas generales mencionados pudieran desprenderse otros más que el autor no trabaja: ideología, poder, manipulación de información, etc., los que también parecen de suma importancia en la comprensión del contexto social de las cifras. Aún así, el texto incita a la discusión y parece de relevancia sociológica, siendo sus temáticas lo suficientemente amplias como para trascender la especificidad de la cultura norteamericana y permitir hacernos preguntas sobre el tratamiento de las cifras en nuestro contexto particular.

Pero además el texto resulta de interés para las ciencias sociales y la sociología. No sólo porque el mismo autor incite a éstas a hacerse cargo de la educación estadística, sino porque permite poner en cuestión los sentidos comunes propios de las disciplinas. En ciencias sociales se asume como algo evidente el proceso social que está tras la producción de los datos, en este sentido ¿no es algo obvio lo que nos plantea Best? La respuesta es doble. Si bien la contextualización social de las cifras -e incluso la crítica- es algo que en ciencias sociales cae por su propio peso, ¿está realmente presente la crítica estadística en la práctica científica?, ¿se asumen con responsabilidad las consecuencias públicas de producir datos?, ¿no será que la crítica naturalizada pierde su aguijón y se transforma en trabajo rutinario? En este sentido, valga el aporte de Best y la idea de alfabetización estadística.

Ahora bien, más allá de la noción de crítica que pudiera manifestar el autor -uno pudiera preguntarse hacia dónde se dirige la crítica que plantea, si es que hay o no una pregunta por lo político- y más allá de las limitaciones que este libro pudiera presentar en términos de profundización o alcance de las temáticas ligadas a la presentación de los datos en 
la opinión pública, nos propone una vía de análisis así como también una discusión en términos de pensamiento crítico y de autoobservación disciplinar, una reflexión sobre lo que recibimos y cómo lo recibimos, así como también -y que a juicio de quien escribe es lo más relevante- sobre nuestro proceder científico, nuestro sentido común y nuestras pretensiones críticas. 